\title{
Interactive comment on "Technical Note: Monitoring streamflow generation processes at Cape Fear" by Flavia Tauro et al.
}

\section{Anonymous Referee \#1}

Received and published: 23 October 2016

The authors describe a sophisticated monitoring system in an artificial slope of dimensions $7 \mathrm{~m}$ (long) by $7 \mathrm{~m}$ (wide). Based on the stated volume $(40 \mathrm{m3})$, the average soil depth was $0.81 \mathrm{~m}$, although it is not stated whether this depth was uniform. The impermeable barrier at the base of the plot and the borders along the sides of the plot, impose artificial boundary conditions which facilitate simplifying the hydrologic conditions and controlling water fluxes for basic understanding of hillslope hydrological processes, but (on the other hand) are a bit unrealistic except for artificial slopes and very homogeneous soils. The objective of the paper, although not specifically stated, appears to be to study the hydrological response to external rainfall through this "proof-of-concept" the thrust of the paper is on the uniqueness of this proof-of-concept methodology.

While the experimental setup is a bit unique, I take issue that this could be considered 
a "proof-of-concept". Interestingly, in the Introduction, the authors mostly describe recent hillslope plot studies (Biosphere 2 Hillslope; Hydrohill; etc.), but ignore important earlier work. Specifically, they do not mention the classic Hewlett \& Hibbert plot study in the Coweeta Experimental Watershed - results were published in the early 1960's and formed the basis for the 'variable source area' concept for streamflow generation. Furthermore, there have been a many studies (dating back into at least the 1970's) conducted in large flumes and constructed hillslopes to assess the interactions of pore water pressure generation and slope stability. Given all of this previous work in constructed hillslopes, I fail to see how the study described in this paper fits the definition of a 'proof-of-concept'.

Based on my assessment, I suggest that the authors conduct a series of unique hydrologic experiments in this artificial hillslope. Being able to capture natural rain events is a definite advantage. The fluorescent dye tracing can be used as described to examine the initiation of erosion features for different cover conditions, but this will take multiple experiments. In short, there is good potential here to utilise this experimental setup to examine some basic surface hydrology and erosion phenomena, but describing just one storm sequence is insufficient for a publication in HESS.

\section{Other Comments:}

Introduction: I have no idea why the authors selected the references that are listed as examples of hydrologic processes in natural and artificial slopes. Many seem inappropriate to the discussion, and only a few are early important works. The statement on page 2, lines 20-21 appears to be a quote, but makes little contribution to the discussion. The statement on page 3, lines 7-8 is incorrect - just because the system is exposed to natural events does not mean it allows for establishment of hydrologic processes found in natural ecosystems. The disturbed nature of soil (i.e., no or limited natural soil structure) in the plot is very different from actual hillslope soils.

Section 2.1: I would not categorize the January 29-30 storm as two events given their

Printer-friendly version

Discussion paper
Interactive comment 
proximity - this is really only one storm sequence.

Section 2.2: When and how was the soil placed into this structure? Was the soil left to 'settle' for a long time so that some minimal soil structure could begin to form? Was the soil compacted in layers as it was put into the plot? Was the depth the same throughout the plot $(0.81 \mathrm{~m})$ ? Make it clear that the lower end of the slope was open and allowed to freely drain (or is this not the case)? Assuming this is the case, you should note that this imposes an artificial boundary at the lower slope (i.e., water will not drain until soil is saturated). This could promote saturated overland flow.

Section 2.2.1 Why not try to estimate Ksat from in-situ measurements rather than small cores? You did not show the number of samples analysed to calculate variability (page 4, line 33). Ksat values are typically log-normally distributed, thus conventional CV's are not really appropriate. The statement on Page 5, Lines 9-10 is confusing: you note that the low bulk density of the soil makes it prone to compaction and disturbance of aggregates. I agree about the soil being prone to compaction, but I doubt that this disturbed soil had well-formed aggregates (see my previous comment). On page 5, line 16, please state the specific hydraulic properties you are referring to.

Section 2.2.2 The purpose of the third tank is a bit unclear. A reference is needed for the S.T.S. strain gauge.

Section 2.2.4 Why did you use a 1-D model to simulate flow; of course there should be lateral flow unless the surface conditions were such that most of the rainfall moved downslope as overland flow, and this appears not to be the case.

Section 2.2.7 The statement on Page 8, lines 26-27 is unclear - please rephrase.

Section 3.1 Pg. 9, lines 21-25: These results are completely predictable and widely known. Pg. 9, line 33: turbity is in NTU; suspended sediment is in $\mathrm{mg} / \mathrm{L} \mathrm{Pg.} \mathrm{10,} \mathrm{lines}$ 4-11: It is not clear how the plot configuration may have affected lower slope drainage and the build-up of a water table; see earlier comments. Section 3.2 Page 10, Lines 13-

Printer-friendly version

Discussion paper 
33: These two paragraphs describe issues dealing with "Methods" rather than process understanding derived from results. Page 11, lines 1-6: Do you mean that no rills were present on the soil surface at the onset of the experiment (line 1)? What do you mean by saying "particle transport becomes more regular"? By "remarkable recovery", are you referring to the $97 \%$ recovery?

Section 4 Page 11, lines 8-15: This reiterates the homogeneous conditions, but nothing new is described. Quick response to rainfall is not a new finding. Page 11, line 19: I assume you mean preferential surface pathways - please note that these can lead to rill formation. Page 11, lines 20-21: But Dunne mostly worked in field settings. You never really describe the antecedent soil moisture conditions. Page 12, lines 1-2: I would argue that the specific hydrologic processes that you can derive from plot studies with uniform soils are mostly known. Page 12, lines 8-9: If you want to examine the effects of soil structure and vegetation over time in a single experimental plot like Cape Fear, this would take many years. Page 12, lines 12-14: If you sub-divide the plot, then you would have quite small plots to work with and would lose the concept of a hillslope experiment.

Section 5 The Conclusions are quite obvious.

Interactive comment on Hydrol. Earth Syst. Sci. Discuss., doi:10.5194/hess-2016-501, 2016. 